\title{
Process chains in the development of remote deposits of the North
}

\author{
Vladimir Gavrilov ${ }^{1 *}$ and Vladislav Fyodorov ${ }^{1}$ \\ ${ }^{1}$ Mining Institute of the North, Siberian Branch, Russian Academy of Sciences, Yakutsk, Russia
}

\begin{abstract}
The low level of development of remote northern regions of Russia predetermines a very high dependence of the mining and processing enterprises of that area on the import of material and technical resources and the export of products obtained after mining. Infrastructural restrictions and a continuous increase in the costs of goods and services, often outstripping the growth of prices for mineral wealth, increase the risks in the implementation of investment projects and worsen their economic performance. The results of an analysis of long, complex and multi-link process chains formed by mining enterprises of the polar regions of Yakutia are presented. The procedure of supply, extraction, logistics and primary processing of mineral wealth requires improvement. It is shown that mining enterprises by volume and type of output can be divided into four groups. On the basis of a comprehensive review of the factors of external and internal environment, proposals are formulated to improve the management of the delivery of cargos and delivery of finished products within supply chains. The prerequisites for replacing part of the delivered fuel and energy resources with local coal are considered. Keywords. Remote area, supply chain, deposit, logistics, export, coal, quality
\end{abstract}

\section{INTRODUCTION}

In Russia, the issues of social and economic development of the northern regions of the Far East and Siberia are given great attention [1-4]. The basic elements for these territories are often operating or new mining enterprises, supplemented by logistics, energy and other infrastructure facilities. Effective exploitation of the deposits provides for the expansion of the range, increase in the competitiveness and quality of mineral products, introduction of energy-saving technologies, integrated use of minerals [4].

For mining in the North, the main cost drivers (in addition to extreme natural and climatic conditions) are: remoteness of development facilities from consumption centers; a low level of development of transport-logistical and fuel-energy sectors in the region; significant cost of any types of energy consumed; almost full dependence on the delivery of material and technical resources and outflow of products; limited in time, complex and multi-tiered "Northern delivery". An analysis in [5-6, etc.] shows that the application of traditional approaches, principles and methods of doing business does not compensate for the influence of these factors. And the proposed measures aimed at increasing the

* Corresponding author: gvlugorsk@mail.ru 
efficiency of development of deposits in remote areas practically do not provide additional competitive opportunities.

The polar regions of Yakutia, being a case study for analyzing the supply chains of mining and enrichment enterprises, mining, primary processing and logistics of mineral resources, are outsiders among the northern regions of Russia in terms of their level of social and economic development. In general, they can be classified as the territories of perspective development, based on the deposits being surveyed and the developed transport routes, or wildlife areas [1]. In such a situation, it is necessary to develop and implement measures aimed, if not to complete overcoming the existing difficulties, then at least partially neutralizing them. An important direction of increasing the level of management in the development of subsurface resources is various aspects of improving the multi-tiered supply chains of the material and technical resources generated by the regional mining and technical systems for the needs of those systems and the outflow of the products they make.

\section{MATERIALS AND METHODS}

The basis for studying in the polar zone of Yakutia of existing and promising process chains, generated by deposits of mineral resources of various types and values, was a number of sources of information. Their collection, processing, interpretation and generalization, carried out using the methods of analogies, comparisons, SWOT and PEST analysis, made it possible to assess the current situation with the delivery of goods and outflow of products to/from mining enterprises, and identify ways of improving logistics. The paper considered information on the experience accumulated in that field or the solutions planned for adoption in companies of various capacities (Alrosa, Almazy Anabara, Geoprommaining, Gold Indigir, Tarynskaya zolotorudnaya kompaniya, Prognoz, NordGold, Poisk-Zoloto, Zyryansky razrez, etc.).

In addition, two main points were taken into account. 1. The most effective development and use of mineral resources in the region is achieved by considering all the links of process chains as complex dynamically changing systems for the development of geo-resources, functioning according to criteria agreed between participants (links) [7]. With this approach, process chains oriented to domestic and foreign highly competitive markets can turn into chains of creating real value added. Their functioning can and should be carried out in accordance with the principles and conditions set forth, for example, in [8, 9]. 2. Existing reserves of minerals in the region should be regarded as a probabilistic, to a certain extent, unreliable geological resource. It, in the face of changing, difficult to forecast in dynamics market value of different types and varieties of mineral raw materials, requires additional study at different stages of exploration, design, operational exploration and development of deposits [10]. The purpose of this work is the maximum adaptation of the quality of extracted minerals and the products obtained from them to the existing and / or expected needs of particular end-users.

\section{RESULTS AND DISCUSSION}

The existing facilities in the polar zone of Yakutia to extract diamonds and gold from placer deposits and coal for local needs are planned to be supplemented with the development of new deposits. According to the strategy of development of Yakutia for the future up to 2030 , with the definition of the target vision until 2050, it is planned to gradually develop the deposits of diamonds, gold, silver, rare earths, polymetals, hydrocarbons, coal and other minerals (Fig.). 
The specifics of the region in question predetermine an increased attention to the functioning of transport and logistics links in chains related to the inflow of goods (mining machines, general special equipment, spare parts, fuel and energy resources, lubricants, most types of products, overalls, etc.) and outflow of finished products. These elements in a significant, often decisive, degree form the level of accessibility of any field. Accessibility here refers to the property of the system "society - mineral resources", which characterizes the possibility of efficient and safe consumption of resources depending on their condition, demand and the process level reached [11]. In assessing accessibility, one should take into account: 1) geographic and mining-geological features of the region; 2) attractiveness of reserves, depending on their qualitative and quantitative parameters, the idea of which changes at different stages of development of deposits; 3) variation in demand for raw materials with changes in demand and price adjustments; 4) influence of process and organizational levels of production in the mining and processing of raw materials on the efficiency of extraction of useful components at each point in time; 5) attractiveness of subsoil development projects for investors in comparison with alternative options in other regions and industries.

\subsection{Supply of fuel, energy and material resources}

Enterprises that work out or plan to develop deposits in the area under consideration have a very high dependence on the inflow of virtually all types of cargo. This is due to the low or pioneering level of socio-economic development of the region, the lack of any manufacturers, and often even suppliers of material and technical products, limited opportunities for using local fuel and energy resources, despite their availability.

Companies in the practice of their operation use, with a variety of efficiency, a number of transport and logistics schemes to achieve normal maintenance of their production activities (Fig.1). The following types of transport are used: railway (delivery of cargo to the entrance ports); water (river and sea); automobile (year-round and seasonal for "winter roads"); air (airplanes and helicopters). Due to the multilevel routes of delivery, the mismatch between the timing of river and sea navigation, the work of "winter roads", the shallow water of rivers, their estuaries and ocean parts of the route, the cargo is forced to undergo a series of stages of long intermediate and basic storage. There is an urgent need to maintain large reserves, which leads to the freezing of significant working capital, the attraction of credit money. Long-term (up to 2.5 years) delivery times, change of seasons, precipitation and numerous transshipments generate significant losses in the quantity and quality of both inflowing and outflowing cargos. These losses often exceed normative standards. Considering this, the enterprises pay some attention to the organization of storage and transshipment of goods from one type of transport to another. Warehouses of open and closed storage, warm and cold, own and leased, have found application in logistics. 


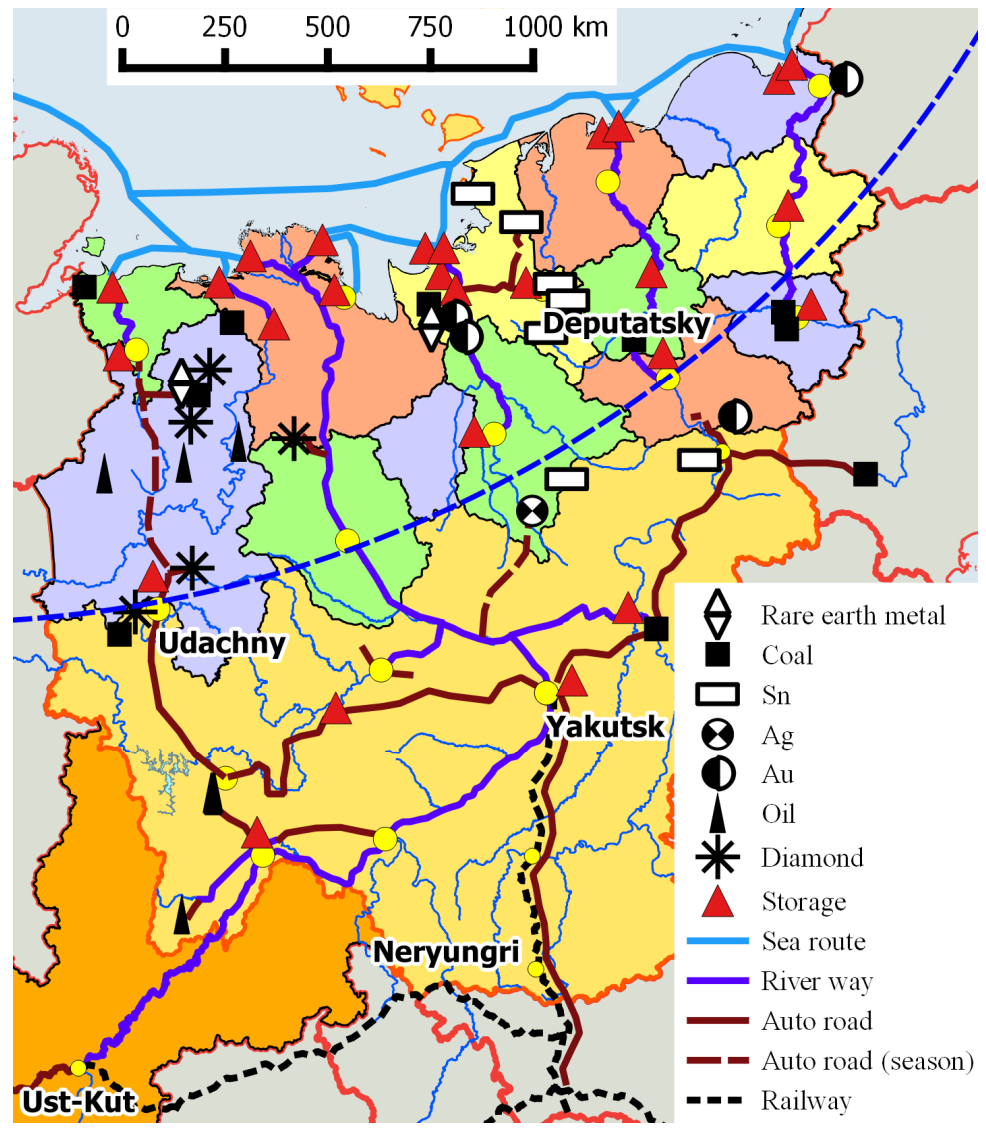

Fig. 1. Deposits of the polar Yakutia area and logistics in the course of their development

In the structure of the cost of almost any enterprise in the North, fuel and energy account for 30 to $60 \%$. In the conditions of a continuous increase in costs for them, often outstripping the rise in prices for finished products, the urgency of replacing expensive fuel with other sources of energy is constantly increasing. Aa analysis of projects for developing deposits in the region shows that medium and small enterprises do not sufficiently consider alternative schemes for covering their needs with local types of resources.

The imposition of a fuel and energy resource map in the region under consideration on a map of the location of deposits to be developed or planned for development shows that under certain circumstances it would be possible to replace some of very expensive hydrocarbons and coal delivered with local resources to reduce total costs.

Practice of operation of AK Alrosa shows an example of such a substitution. At present, the use of local natural gas is started as a fuel for highway and public transport. Even conversion of mine machinery to gas fuel is being considered. When Deputatsky MPP (mining of ore and placer tin) worked, the question of developing a local brown coal pit and construction of a coal-fired CHP plant was seriously raised. CHP as a result was built many years later, but it was not fed by local coal, but expensive coal delivered from Dzhebariki Khaya pit (the center of Yakutia) or from even more remote Kuzbass region.

Low demand for local coal, despite its wide distribution, including in the locations of promising deposits (see the figure), is associated with a number of reasons, namely: low quality of supplied fuel, often not satisfying the consumer; traditional opinion of the low efficiency of its use, in comparison with hydrocarbons. Both reasons can be partially 
neutralized. The first is solved through the integrated management of coal quality in exploration, production and supply to consumers, with appropriate adjustments to planning, production and additional fuel treatment for supplies, including remote consumers [12]. The second solution, similar to the regions and countries leading in this area, is achieved by applying modern small-scale coal processing technologies to produce briquettes, semi-coke, gasification, pyrolysis, use of cogeneration for generating electric and heat energy. The study of the reasons preventing this and the development of proposals for their elimination are a separate topic not considered further.

\subsection{Outflow of mineral wealth}

From the point of view of transportation of the products obtained, by the degree of influence of the logistic component on the efficiency of development of the area's deposits, georeources can be divided into four conditional groups. 1. Having at the output of a small amount of useful minerals with high consumer value and the degree of readiness (diamonds, precious metals). 2. Forming volumes in the first tens of thousands tons (concentrates of tin, rare earths, antimony, other strategic metals). 3. Creating volumes of finished products, measured in hundreds of thousands and millions of tons per year (hydrocarbons, coal, ferrous ores) and requiring high-performance transport schemes for year-round use. 4. Used for extremely limited domestic consumption in the region (local fuel and energy resources, building materials).

In the structure of the cost price, the share of costs associated with the delivery of mineral and raw materials from the production sites to the places of consumption, processing or transfer of ownership varies from the first percent to the level making seemingly accessible deposits economically unacceptable.

The most simple and effective in the region in terms of logistics are diamonds and precious metals. They are shipped for sorting, faceting, refining mainly by air. Shipping of ore concentrates of less valuable or more voluminous types of minerals by air is often not available. Relatively positive experience of several years of shipping tin concentrate from deposits near Deputatsky township for processing in Novosibirsk can be explained by a favorable combination of circumstances: the presence of particularly heavy aircraft and an airport capable of receiving them, the ability to load aircrafts round-trip, relatively high prices on tin in the market.

Long distances, pronounced seasonality and high cost of services of other types of transport available in the region dramatically reduce the investment attractiveness of deposits with less valuable types of mineral resources. A study of the experience of mining enterprises in the north of Yakutia shows that the solution of tasks for shipping products even for group 2 is already associated with certain difficulties, not to mention group 3 . There are cases when, even at distances of $15-20 \mathrm{~km}$, the delivery of ore to the concentrating plant in the conditions of the North-East of Russia becomes more expensive than mining and comparable to its processing. And the decision to deliver mined ore from perspective diamond pipes located $170 \mathrm{~km}$ from the concentrator in Udachny led to the need for new trunk road trains, construction of special haul roads.

When considering the enterprises associated with the third group, the complexity of organizing at least relatively normal logistics should be well represented. Earlier it was shown [13] that the implementation of the project on the supply of coal for export from Zyryansky Basin on the Kolyma is economically inexpedient. The cost of ordinary coal already at the mouth of the river was $40-60 \%$ higher than the price of steam coal concentrate with higher quality on CIF Japan terms. When organizing large-scale coal and boghead mining at the Taimylyrsk field, located near the sea coast, the issue will arise of integrating the facility into the logistics of the Northern Sea Route with the construction of 
a deep-sea port and expensive dredging operations. This project can be implemented only under very favorable conditions, for example, if oil and gas production starts in the region. But this is a very distant prospect.

For enterprises in the fourth group, it is also very important what distance they are from consumers. In existing schemes of coal delivery to the polar regions of Yakutia, transportation and storage account for up to $50-65 \%$ of total costs at the place of consumption, and in the most inaccessible reaching $80-85 \%$ [14]. In such a situation, the question arises about the construction of pits (coal) or quarries (building materials) of low capacity to meet local, very limited needs.

\section{CONCLUSIONS}

One of the mechanisms for improving the performance of process chains formed in remote polar regions by mining enterprises is to improve the processes of supplying them with the necessary resources and shipping the extracted mineral wealth. The use of results of the proposed differentiation of enterprises into four groups, taking into account the features of the chains, the volume and type of products, makes it possible to reduce the risks of making irrational decisions when assessing and implementing projects.

Almost non-alternative use of expensive hydrocarbon fuel at mining enterprises of the North for the development of mechanical, electrical and thermal energy leads to an increase in the cost of all process operations. The use of local ordinary and graded coal, which can be mined from deposits located in close proximity to mining enterprises that extract other types of minerals, makes it possible to reduce the development costs of both the first and latter. To generate thermal and electrical energy from coal, it is advisable to use cogeneration schemes. Deeper coal processing should be carried out using low-tonnage technologies to produce liquid and gaseous fuels, semi-coke and briquettes. Deep processing will promote the growth of coal consumption in the region and improve the performance of extractive companies.

In the existing institutional conditions in the country, enterprises do not have sufficient incentives and opportunities to implement such activities without governmental support, which requires separate consideration.

The reported research was funded by Russian Foundation for Basic Research and the government of the Yakutia region of the Russian Federation, grant No.18-45-140048 p_a.

\section{References}

1. State program of the Russian Federation "Social and economic development of the Arctic zone of the Russian Federation for the period until 2020". Approved by the Government of the Russian Federation 21.04.2014. No.366-p

2. D.A. Dodin, D.V. Kaminskii, O.I. Suprunenko, V.I. Pavlenko, Arctic: Ecology and Economy, 4 (2011)

3. A.E. Sevastianova, Region: Economics and Sociology, 3 (2013)

4. G.V. Baturova, A.M. Konovalov, Region: Economics and Sociology, 4 (2015)

5. S.V. Kornilkov, V.L. Iakovlev, Iu.A. Mamaev, A.P. Van-Van-E, News of the Higher Institutions. Mining Magazine, 6 (2012)

6. M.Iu. Kharitonova, N.A. Macko, Geology and Mineral Resources of Siberia, 3 (2013)

7. S.A. Batugin, S.M. Tkach, N.S. Batugina, V.L. Gavrilov, Mining informationanalytical bulletin, 9 (2012) 
8. R. Kaplinski, Spreading the Gains of Globalisation: What Can Be Learned from Value Chains Analysis (Translation from English, Moscow, GU VShE, 2002)

9. M.E. Porter, Competitive Advantage: Creating and Sustaining Superior Performance (Translation from English, Moscow, Al'pina Biznes Buks, 2005)

10. Geotechnologies of Open-pit Development of Deposits with Complex Mining and Geological Conditions; Ed. S.M. Tkach (Novosibirsk, Geo, 2013)

11. A.A. Peshkov, N.A. Macko, Availability of mineral resources (Moscow, Nauka, 2004)

12. V.I. Fedorov, V.L. Gavrilov, E.A. Khoiutanov, Advances in Current Natural Sciences, 9 (2017)

13. V.L. Gavrilov, All-Russian scientific seminar "Actual problems, directions and mechanisms of development, productive forces of the North-2014": in 2 parts, 1 (2014)

14. N.S. Batugina, V.L. Gavrilov, E.G. Shepeleva, ECO, 2 (2017) 